\title{
Diadenosine Polyphosphates in Tears of Sjögren Syndrome Patients
}

\author{
Gonzalo Carracedo, ${ }^{1}$ Assumpta Peral, ${ }^{1}$ and Jesús Pintor ${ }^{2}$
}

Purpose. To analyze the levels of diadenosine tetraphosphate $\left(\mathrm{Ap}_{4} \mathrm{~A}\right)$ and diadenosine pentaphosphate $\left(\mathrm{Ap}_{5} \mathrm{~A}\right)$ in tears of subjects with Sjögren syndrome and to compare them with those in a control group.

Methods. Twelve subjects with a diagnosis of Sjögren syndrome and 20 healthy control subjects were invited to participate in the present study. Schirmer strips were used to measure tear secretion (Schirmer I test) and to collect tears. $\mathrm{Ap}_{4} \mathrm{~A}$ and $\mathrm{Ap}_{5} \mathrm{~A}$ were measured by high-pressure liquid chromatography (HPLC), and a dry eye questionnaire (DEQ) was used to evaluate dry eye symptomatology.

Results. The mean concentrations of $A_{4} A$ and $A_{p_{5}} A$ in the Sjögren syndrome group were $2.54 \pm 1.02$ and $26.13 \pm 6.95$ $\mu \mathrm{M}$, respectively. This group of patients was divided in two subgroups: four patients with normal tear production and eight patients with low tear production. Concentrations of $\mathrm{Ap}_{4} \mathrm{~A}$, and $\mathrm{Ap}_{5} \mathrm{~A}$ in patients with normal tear production (Schirmer test result, $12.3 \pm 1.2 \mathrm{~mm}$ ) were $0.47 \pm 0.20$ and $8.03 \pm 3.27$ $\mu \mathrm{M}$, respectively. In the patients with low tear production (Schirmer test result, $1.0 \pm 0.3 \mathrm{~mm}$ ), the concentrations were $4.09 \pm 1.36$ and $39.51 \pm 8.46 \mu \mathrm{M}$, respectively and in the control group, $0.13 \pm 0.03$ and $0.04 \pm 0.02 \mu \mathrm{M}$, respectively.

Concuusions. Patients with Sjögren syndrome have abnormally elevated concentrations of diadenosine polyphosphates, indicating that these compounds could be used in the diagnosis of this disease. (Invest Ophthalmol Vis Sci. 2010;51:5452-5459) DOI:10.1167/iovs.09-5088

$S^{j}$ ögren's syndrome is a chronic autoimmune disease in which the body's immune system mistakenly attacks its own exocrine glands, particularly the salivary and the main lachrymal glands. Lymphocytes infiltrate the glands and cause a decrease in their secretions. ${ }^{1}$ This syndrome is classified as primary when only the exocrine glands are affected and as secondary when it is associated with other systemic diseases. ${ }^{2}$ Primary Sjögren syndrome has a prevalence rate of $0.5 \%$ and occurs more frequently in women than in men $(9: 1) .{ }^{3}$ It is diagnosed late, usually at 45 to 50 years of age, most often in an ophthalmologist's or optometrist's consulting room. ${ }^{4}$

From the ${ }^{1}$ Departamento de Óptica II (Optometría y Visión), Escuela Universitaria de Óptica, Universidad Complutense de Madrid, Madrid, Spain; ${ }^{2}$ Departamento de Bioquímica y Biología Molecular IV, Escuela Universitaria de Óptica, Universidad Complutense de Madrid, Madrid, Spain

Supported by Research Grants (GR58-08) from Banco Santander Central Hispano and Universidad Complutense de Madrid, Spain.

Submitted for publication December 17, 2009; revised March 18 and May 4, 2010; accepted May 6, 2010.

Disclosure: G. Carracedo, None; A. Peral, None; J. Pintor, None Corresponding author: Gonzalo Carracedo, Department de Óptica II (Optometría y Visión), Escuela Universitaria de Optica, Universidad Complutense de Madrid, Avda Arcos de Jalón 118, 28037 Madrid, Spain; jgcarrac@opt.ucm.es.
Sjögren patients report dry eye, sandy sensation, and irritated eyes as common symptoms. The principal ocular signs of the disease are aqueous tear deficiency and severe corneal surface damage. It also presents systemic manifestations such as xerostomia, dry skin and mouth, respiratory insufficiency, and fatigue. ${ }^{1,5}$ At the beginning of the disease, when the typical signs and symptoms are often lacking or are not entirely expressed, diagnosis is complicated. Ocular signs and identified through assessment of tear production and ocular surface staining. It is also important to perform a test for dry eye symptomatology as suggested by the Dry Eye Workshop 2007.6 The presence of the disease is fully confirmed by the presence of systemic signs such as lymphocyte infiltration of the salivary glands or the presence of antibody markers such as anti-Ro or -La, together with the existence of at least one systemic symptom such as dry mouth. ${ }^{2}$

The presence of diadenosine polyphosphates in the tear film was described for the first time in 2002. ${ }^{7}$ These compounds $\mathrm{Ap}_{n} \mathrm{~A}(n=2-7)$, formed by two adenosine molecules joined by a variable phosphate chain, are naturally occurring nucleotides with intra- and extracellular physiological actions. ${ }^{8}$ Since 2000 , the activities of these nucleotides have been investigated in ocular tissues, and their involvements in some aspects of ocular physiology have been described.

In the tear film, it is known that diadenosine polyphosphate concentrations rise in patients with dry eye symptoms, with either normal or with low tear production, suggesting the possibility that these compounds could be objective parameters for grading dry eye. ${ }^{9}$ Moreover, a single-dose topical application of the dinucleotides $A p_{4} A, A p_{5} A$, and $A p_{6} A$ in rabbits, can stimulate tear secretion, giving these compounds a secretagogic action. ${ }^{10}$ Concerning the ocular surface, $\mathrm{Ap}_{4} \mathrm{~A}$ improves the rate of wound healing in the cornea of New Zealand White rabbits. ${ }^{11}$ Also, intraocular pressure (IOP) can be modulated by the action of some dinucleotides in rabbits. ${ }^{12}$

The present experimental work describes variations in the levels of diadenosine polyphosphates in Sjögren syndrome patients' tears and how these compounds are abnormally increased. Moreover, since Sjögren syndrome diagnosis is invasive and complex, it is suggested that the determination of these dinucleotides would be a complementary approach that can be used to prediagnose this disease.

\section{Methods}

The study was conducted in compliance with good clinical practice guidelines, institutional review board regulations, informed consent regulations, and the tenets of the Declaration of Helsinki (World Medical Association, 2008). All the subjects enrolled in the study were adults older than 18 years and were able to give informed consent.

\section{Subjects}

Twelve subjects, 9 women and 3 men aged between 35 and 66 years (mean, $52.8 \pm 4.2$ ), who had received a diagnosis of primary Sjögren syndrome in the past 5 years (mean, $3.4 \pm 0.9$ ) and were enrolled in 
the Spanish Sjögren syndrome Society, participated voluntarily in the study. In all the patients, the disease was diagnosed according to the American-European Consensus Group (AECG) on diagnostic criteria for Sjögren syndrome (Vitali et al. ${ }^{2}$ ). This Sjögren syndrome group was divided into two subgroups, patients who had a Schirmer test result of more than $5 \mathrm{~mm}$ (Sjögren syndrome normal tear subgroup) and patients who had results below $5 \mathrm{~mm}$ (Sjögren syndrome low tear subgroup).

The control group constituted 11 female and 9 male healthy volunteers aged between 34 and 63 years (mean $41.7 \pm 1.7$ ), with no evidence of dry eye symptoms or signs.

Schirmer strips were used to measure tear secretion (Schirmer I test) and to collect tears. The measurements were made early in the morning, before the instillation of any ocular medications. Every patient used artificial tears (Viscofresh 1\%; Allergan, Irvine, CA) at least five times per day. In addition, both groups were invited to complete the Dry Eye Questionnaire (DEQ) developed by Begley et al. ${ }^{13}$

\section{Trials}

Tear Collection. Tear secretion was measured by using the Schirmer I test (without anesthesia). The tear collection was always performed according to Van Bijsterveld criteria. ${ }^{14}$ The Schirmer strip was placed on the temporal tarsal conjunctiva of the lower lid for 5 minutes with the eyes closed. The volume of tears, in millimeters of moistened strip, was recorded, and the Schirmer strips were placed in tubes (Eppendorf, Fremont, CA) containing $500 \mu \mathrm{L}$ of purified water (Ultrapure; Millipore, Billerica, MA). The samples were then frozen until they were analyzed by high pressure liquid chromatography (HPLC).
Tear Processing and HPLC Analysis. After thawing, the samples were strongly vortexed for 5 minutes. The strips were carefully rinsed, and the liquid in the tube was heated in a $100^{\circ} \mathrm{C}$ bath for 20 minutes, to precipitate the proteins. To pellet the proteins, we centrifuged the tubes at $4000 \mathrm{rpm}$ for 30 minutes. Diadenosine polyphosphates are not degraded by this treatment, as previously demonstrated. ${ }^{15}$ Supernatants were chromatographed ${ }^{16}$ through a silica-based hydrophilic anion exchanger (SEP-PAK Accell QMA cartridge; Waters, Milford, MA). Briefly, $250 \mu \mathrm{L}$ of the supernatant was passed through the cartridges which had been equilibrated with $3 \mathrm{~mL}$ of distilled water. Elution of the nucleotides and dinucleotides was performed by applying $1 \mathrm{~mL}$ of a solution containing $0.2 \mathrm{M} \mathrm{KCl}$ and $0.1 \mathrm{M}$ $\mathrm{HCl}$. Before injection into the HPLC, the samples were neutralized with $\mathrm{KOH}$. The eluents were injected at a volume of 10 to $100 \mu \mathrm{L}$.

Determination and quantification of diadenosine polyphosphates were performed by HPLC. The chromatographic system consisted of an isocratic HPLC pump (model 1515; Waters), a dual-absorbance detector (model 2487; Waters), and an injector (Reodyne; Perkin Elmer, Boston, MA), all managed by the software (Breeze; Waters). The column was a C18, $15 \mathrm{~cm}$ in length, $0.4 \mathrm{~cm}$ in diameter (Novapack; Waters). The system was equilibrated overnight with the following mobile phase: $0.1 \mathrm{M} \mathrm{KH}_{2} \mathrm{PO}_{4}, 2 \mathrm{mM}$ tetrabutyl ammonium, and $17 \%$ acetonitrile $(\mathrm{pH} 7.5) .{ }^{17}$ Detection was monitored at $260 \mathrm{~nm}$ wavelength. All the peaks identified as putative dinucleotides were taken for phosphodiesterase treatment. Phosphodiesterase from Crotalus adamanteus (EC 3.1.4.1) from Sigma-Aldrich (St. Louis, MO), at a concentration of $1.0 \mathrm{U} / \mathrm{mL}$, was incubated at room temperature for 30 minutes with the corresponding putative dinucleotide. The digestion products
A

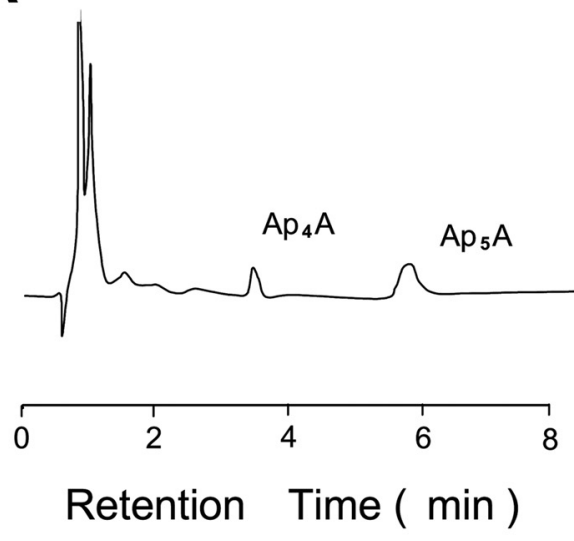

B
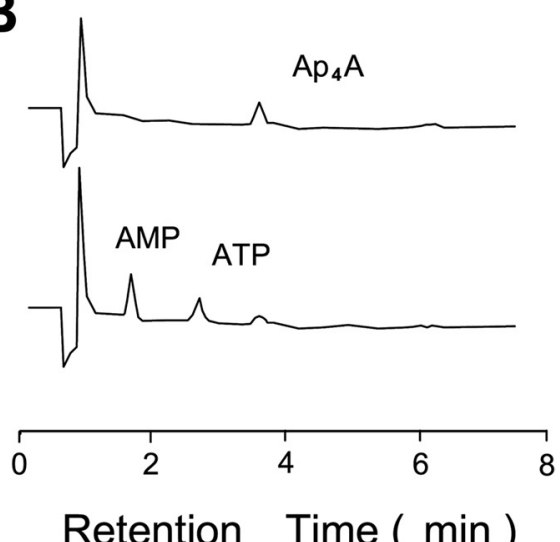

Retention Time ( $\min$ )

0.0002

AUFS I

Figure 1. Demonstration of the presence of diadenosine polyphosphates in tears of Sjögren syndrome patients. (A) Chromatographic profile of a sample showing the presence of $A p_{4} A$ and $A p_{5} A$ in a sample of tears from a Sjögren syndrome patient. (B) Rechromatography of the $\mathrm{Ap}_{4} \mathrm{~A}$ shown in (A) after treatment with phosphodiesterase, demonstrating the cleavage of the dinucleotide and the formation of AMP and ATP. (C) $A_{p_{5}} \mathrm{~A}$ from (A) after treatment with phosphodiesterase showing the appearance of AMP and Ap4. (D) Standard injection of commercial adenine mono- and dinucleotides

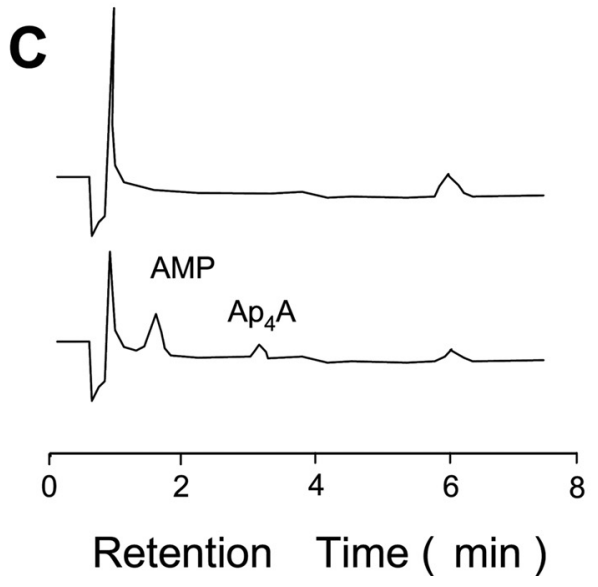

D

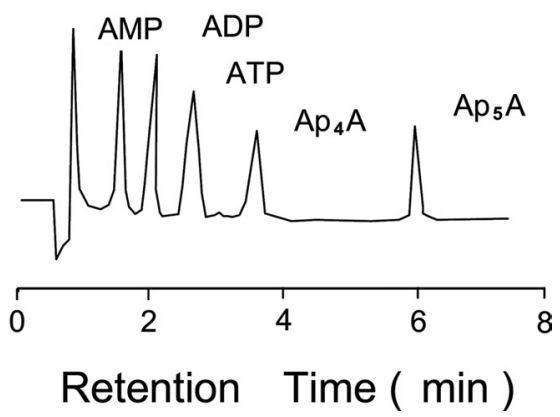




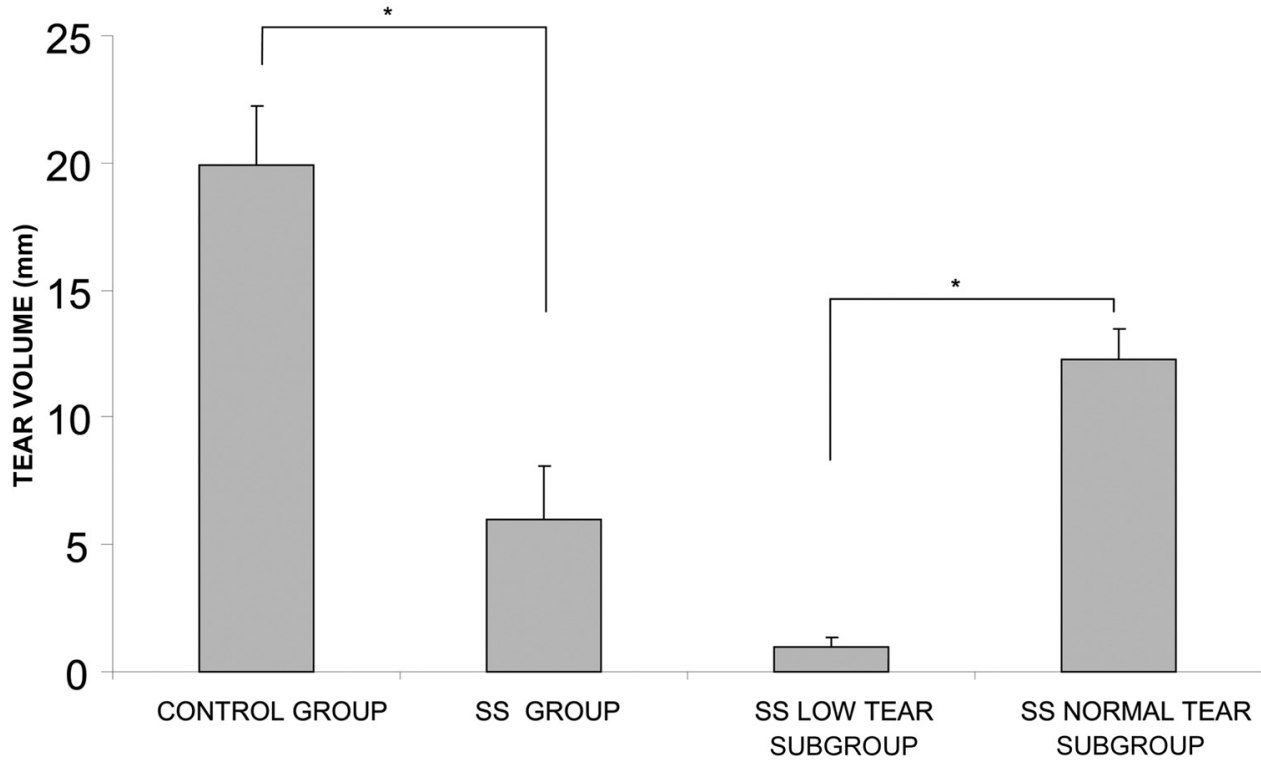

Figure 2. Schirmer I test in the Sjögren syndrome patients and normal subjects. Tear secretion was significantly lower in the Sjögren syndrome group than in the control group. The Sjögren syndrome group could be split into two subgroups, one with low tear secretion and one with normal tear secretion. ${ }^{*} P<$ 0.05 , Student's $t$-test. were analyzed by HPLC. Peaks were transformed into concentrations by means of external standards of known concentrations of diadenosine polyphosphates.

In the tear samples, two peaks were identified as $A p_{4} A$ and $A p_{5} A$, according to the retention times (Fig. 1A). To confirm the nature of the putative $A p_{4} A$ and $A p_{5} A$, both peaks were individually collected and treated with phosphodiesterase from Crotalus adamanteus (Figs. 1B, 1C). The putative $A_{p_{4}} A$ produced two peaks after the enzyme action that were identified as AMP and ATP, whereas the putative $A_{5} A$ produced AMP and adenosine tetraphosphate. These results indicate that these two original peaks corresponded to $A_{4} A$ and $A_{5} A$. The comparison of the peaks with the corresponding standards permitted quantification of these two dinucleotides in the samples (Fig. 1D).

\section{Dry Eye Questionnaire (DEQ)}

This questionnaire was designed to assess the prevalence, frequency, and diurnal severity of ocular surface symptoms such as discomfort, dryness, visual changes, soreness, and irritation, grittiness and scratchiness, foreign body sensation, burning, light sensitivity, and itching. In the first part of the questionnaire, inquiries regarding the frequency of eight typical symptoms of dry eye were made, in which the patients chose between four different frequencies (rarely, sometimes, frequently, and constantly). The last part of the questionnaire includes questions about computer use, allergies, use of systemic and ocular medications, and ambient conditions that cause dry eye symptoms. ${ }^{13}$

The validation of the Spanish translation of the DEQ was supervised by the Psychology Faculty of the Universidad Complutense de Madrid and the original authors, Carolyn Begley and Robin Chalmers, who verified with a Spanish translator the concordance between the English and Spanish documents.

\section{Statistical Analysis}

The values presented are the mean \pm SEM of the experiments performed (version 15.0 for Windows; SPSS, Inc., Chicago, IL). In the case of Sjögren syndrome subgroups values also are presented as the median (first quartile; third quartile). Normal distribution of variables was assessed by the Kolmogorov-Smirnov normality test.

Sample size calculations were performed with statistical software (Granmo 6.0; Institut Municipal d'Investigación Médica, Barcelona, Spain). With an accepted two-sided statistical significance threshold of 0.05 and a $\beta$ risk of 0.20 and taking into account a 2:1 group ratio (control group to Sjögren syndrome group), 16 subjects were needed in first group and 8 in the second, to find statistically significant differences.

Differences between the Sjögren syndrome and control groups in diadenosine polyphosphates levels were estimated by the Student's $t$-test for independent samples. Because sample sizes of these groups are small, Mann-Whitney U tests were used to compare values between the Sjögren subgroups.

Correlations between ordinal data in the Sjögren syndrome group were assessed by Pearson bivariate regression, and one-way analysis of variance (ANOVA) was used to assess the correlation between diadenosine polyphosphate concentrations and each symptoms' frequency.

For statistical analysis of DEQ symptoms data, we used the authors' test criteria. ${ }^{13}$ These criteria indicate that patients who responded frequently or constantly to the frequency questions were symptomatic. We regarded responses with a score of 4 or 5 to the questions about intensity as signifying that the patient was experiencing intense symptoms. The $\chi^{2}$ test was used to contrast frequencies between groups, and the Wilcoxon test was used to compare the diurnal

TABLE 1. Concentrations of Nucleotides, $A_{4} A$ and $A p_{5} A$, in Control Group and Different Dry Eye Group Severity

\begin{tabular}{cccccc}
\hline $\begin{array}{c}\text { Control Group } \\
(\boldsymbol{n}=\mathbf{2 0})\end{array}$ & $\begin{array}{c}\text { Low Tear } \\
\text { SS Subgroup } \\
(\boldsymbol{n}=\mathbf{8})\end{array}$ & $\begin{array}{c}\text { Low Tear } \\
\text { Non-SS Group } \\
(\boldsymbol{n}=\mathbf{1 2})\end{array}$ & $\begin{array}{c}\text { Normal Tear } \\
\text { SS Subgroup } \\
(\boldsymbol{n}=\mathbf{4})\end{array}$ & $\begin{array}{c}\text { Normal Tear } \\
\text { Non-SS Subgroup } \\
(\boldsymbol{n}=\mathbf{3 4})\end{array}$ \\
\hline $\mathrm{Ap}_{4} \mathrm{~A}$ & $0.126(0.027)$ & $4.09(1.36)$ & $10.68(0.54)$ & $0.47(0.20)$ & $0.587(0.058)$ \\
$\mathrm{Ap}_{5} \mathrm{~A}$ & $0.044(0.023)$ & $39.51(8.45)$ & $12.45(0.08)$ & $8.3(3.27)$ & $0.058(0.003)$ \\
\hline
\end{tabular}

The data presented are mean micromolar concentrations of the two dinucleotides (SD). Groups have been divided as normal or low tear production SS patients and compared with dry eye non-SS patients who have normal or low tear production. 


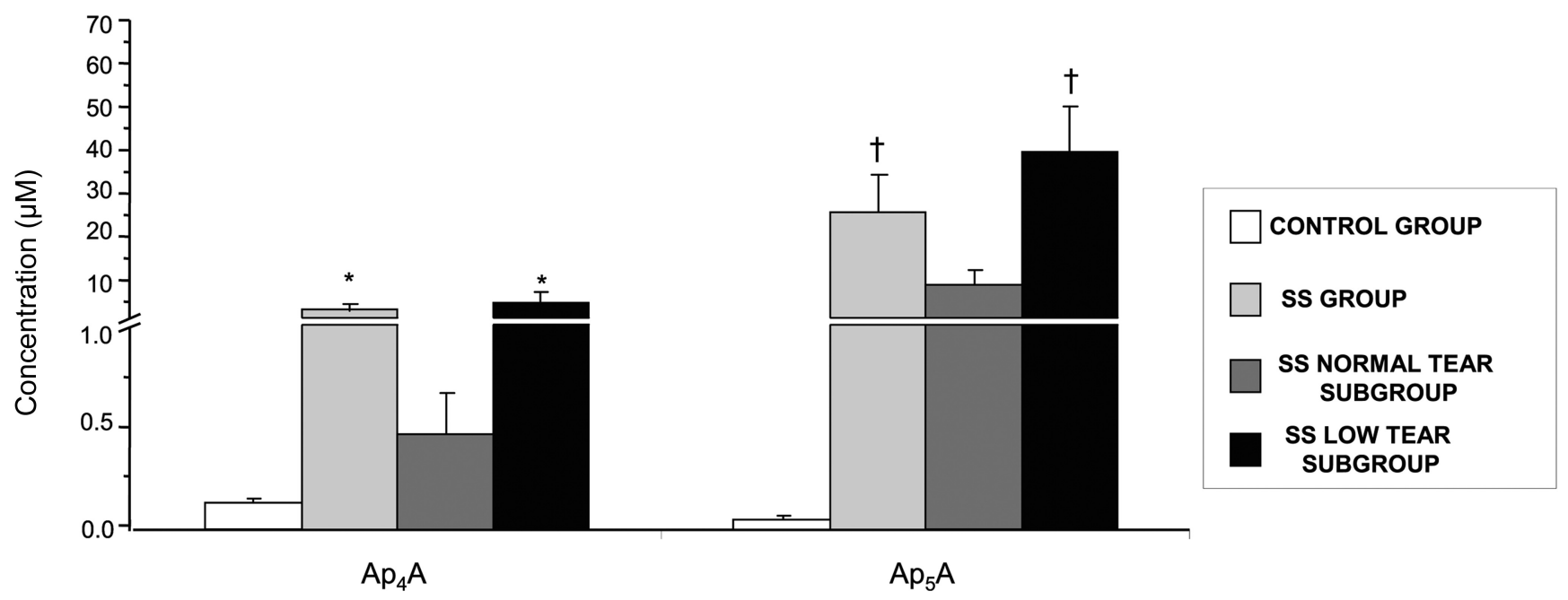

FiguRE 3. Concentrations of $\mathrm{Ap}_{4} \mathrm{~A}$ and $\mathrm{Ap}_{5} \mathrm{~A}$ in the tears of Sjögren syndrome patients and normal subjects. Data are presented for the control group $(n=20)$, Sjögren syndrome group $(n=12)$, and the two patient subgroups: normal $(n=4)$ and low tear $(n=8)$ production. ${ }^{*} P<0.05$ and $\dagger P<0.02$ between Sjögren syndrome subgroups, Wilcoxon Mann Whitney $\mathrm{U}$ test; ${ }^{*} P<0.05$ and $\dagger P<0.01$ control versus Sjögren syndrome group, Student's $t$-test.

changes in symptom intensities (morning to evening). $P<0.05$ was statistically significant.

\section{Results}

\section{Tear Volume Results}

The tear volumes collected in the Sjögren syndrome group resulted in a mean Schirmer strip wetting result of $6 \pm 2.1 \mathrm{~mm}$ $(n=12)$. Four Sjögren patients had a Schirmer test of more than $5 \mathrm{~mm}$ (Sjögren syndrome normal tear subgroup) and a mean of $12.3 \pm 1.2$ and median of $11 \mathrm{~mm}(10 ; 13)$, and eight patients had results below $5 \mathrm{~mm}$ (Sjögren syndrome low tear volume subgroup), with a mean of $1.0 \pm 0.3 \mathrm{~mm}$ and median of $0.75 \mathrm{~mm}$ (first and third quartiles: $0.50 ; 1.00 ; P<0.001$; Sjögren syndrome low tear subgroup versus Sjögren syndrome normal tear subgroup; Mann-Whitney $\mathrm{U}$ test). The mean tear volume in the control group was $19.9 \pm 2.3 \mathrm{~mm}(n=20 ; P<$ 0.001 control group versus Sjögren syndrome group and control group versus Sjögren syndrome normal tear subgroup; Student's $t$-test; Fig. 2).

\section{Nucleotide Analysis in Tears}

The mean concentrations of $A p_{4} A$, and $A p_{5} A$ in the Sjögren syndrome group were $2.54 \pm 1.02$ and $26.13 \pm 6.95 \mu \mathrm{M}$, respectively. In the subgroup of Sjögren syndrome with normal tear secretion $(n=4)$, the concentrations of $\mathrm{Ap}_{4} \mathrm{~A}$ and $\mathrm{Ap}_{5} \mathrm{~A}$ were $0.47 \pm 0.20 \mu \mathrm{M}$ (median, $0.41 \mu \mathrm{M}$; first and third quartiles, $0.12 ; 0.86$ ) and $8.3 \pm 3.27 \mu \mathrm{M}$ (median, $6.4 \mu \mathrm{M}$; 3.01; 14.60), respectively. The subgroup of Sjögren syndrome with low tear secretion $(n=8)$ showed dinucleotide concentrations of $4.09 \pm 1.36 \mu \mathrm{M}$ (median, $4.26 \mu \mathrm{M} ; 0.23$; 6.5) and $39.51 \pm$ $8.45 \mu \mathrm{M}$ (median $36.6 \mu \mathrm{M} ; 17.85 ; 59.14$ ) for $\mathrm{Ap}_{4} \mathrm{~A}$ and $\mathrm{Ap}_{5} \mathrm{~A}$, respectively. These values were significantly different between the subgroups $\left(P<0.05\right.$ and $P<0.02$ for $A_{4} A$ and $A_{4} \mathrm{p}_{5} \mathrm{~A}$, respectively; Mann-Whitney $U$ test). In the control group the concentrations of $\mathrm{Ap}_{4} \mathrm{~A}$ and $\mathrm{Ap}_{5} \mathrm{~A}$ were $0.13 \pm 0.03$ and $0.04 \pm$ $0.02 \mu \mathrm{M}$, respectively $\left(P<0.05\right.$ to $\mathrm{Ap}_{4} \mathrm{~A}$ and $P<0.01$ to $\mathrm{Ap}_{5} \mathrm{~A}$; control group versus Sjögren syndrome group; Student's $t$-test; Table 1, Fig. 3).

\section{DEQ Results}

In the Sjögren syndrome group, the most common responses to all the symptoms were frequently or constantly. In patients with Sjögren syndrome who had a low tear volume, the most frequent symptoms were eye discomfort, dry eyes, irritated eyes, and sensitivity to light. In patients who had a normal tear volume, all had symptoms of foreign body sensation, irritated eyes, eye discomfort, and sensitivity to light. The results of the

TABLE 2. Frequency of Symptoms in Sjögren Syndrome Patients

\begin{tabular}{lcccc}
\hline & & \multicolumn{3}{c}{ Sjögren Syndrome } \\
\cline { 3 - 5 } \multicolumn{1}{c}{ Symptom } & $\begin{array}{c}\text { Control Group } \\
(\boldsymbol{n}=\mathbf{2 0})\end{array}$ & $\begin{array}{c}\text { SS Group } \\
(\boldsymbol{n}=\mathbf{2 0 )}\end{array}$ & $\begin{array}{c}\text { Low Tear Subgroup } \\
(\boldsymbol{n}=\mathbf{8})\end{array}$ & $\begin{array}{c}\text { Normal Tear Subgroup } \\
(\boldsymbol{n}=\mathbf{4})\end{array}$ \\
\hline Discomfort & $3(15)$ & $12(100)$ & $8(100)$ & $4(100)$ \\
Dryness & $1(5)$ & $9(92)$ & $8(100)$ & $3(75)$ \\
Grittiness & $0(0)$ & $6(50)$ & $5(63)$ & $1(25)$ \\
Burning & $0(0)$ & $5(42)$ & $4(50)$ & $3(75)$ \\
Itching & $1(5)$ & $7(67)$ & $5(63)$ & $4(100)$ \\
Foreign body & $0(0)$ & $8(75)$ & $5(63)$ & $4(100)$ \\
Irritation & $0(0)$ & $11(92)$ & $7(88)$ & $1(25)$ \\
Light sensitivity & $4(20)$ & $12(100)$ & $8(100)$ & $5(63)$ \\
Blurring & $1(5)$ & $6(50)$ & $5(0)$ & \\
\hline
\end{tabular}

Symptom distribution and frequency according to patients' reports. The data are the number of patients reporting the respective symptom and, in parentheses, the percentage of patients reporting that symptom. 
control group are shown in Table 2. Significant differences between the Sjögren syndrome groups and control group were observed ( $\chi^{2}$ test, $P<0.01$ ).

Patients assessed the intensity of the symptoms on a scale of 1 to 5, with 1 being the lowest and 5 the highest intensity, and we deemed a symptom intense when patients reported 4 or 5 , according to the DEQ authors' criteria. ${ }^{13}$. In patients with Sjögren syndrome, symptoms such as discomfort, dryness, foreign body, irritated eyes, and blurred vision in- creased in intensity in the evening. The increase in patients with intense symptoms was significantly greater in the low tear subgroup than in the normal tear subgroup (Fig. 4). The increase in the percentage of patients at the end of the day in the subgroup of Sjögren syndrome patients with low tears was statistically significant (Wilcoxon test, $P<0.05$ ) for four of eight symptoms studied. In contrast, in the normal tears subgroup, there were no significant differences for any symptom (Table 3 ). There were no daytime differences in
100

80

60

ㅇำ

40

20

0

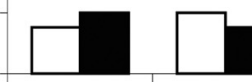

Discomfort Dryness

Grittiness

\section{CONTROL GROUP}
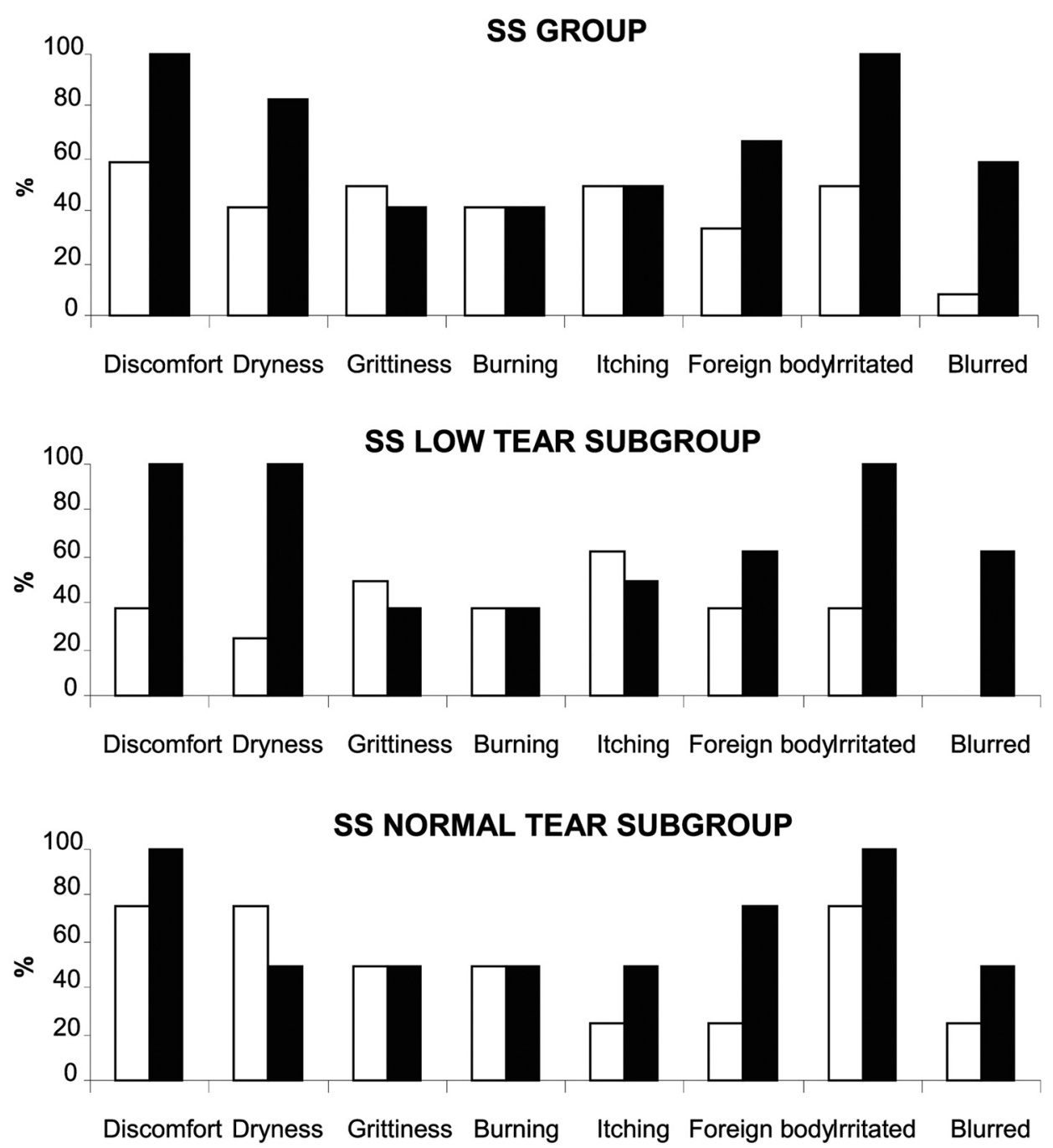

\section{Morning Evening}


TABLE 3. Results of Wilcoxon Signed-Rank Test Comparing the Diurnal Intensity of Symptoms

\begin{tabular}{|c|c|c|c|c|}
\hline \multirow[b]{2}{*}{ Symptom } & \multirow[b]{2}{*}{$\begin{array}{l}\text { Control Group } \\
\quad(n=20)\end{array}$} & \multicolumn{3}{|c|}{ Sjögren Syndrome } \\
\hline & & $\begin{array}{l}\text { SS Group } \\
(n=12)\end{array}$ & $\begin{array}{l}\text { SS Low Tear Subgroup } \\
\qquad(n=8)\end{array}$ & $\begin{array}{l}\text { SS Normal Tear Subgroup } \\
\qquad(n=4)\end{array}$ \\
\hline Discomfort & 0.56 & $0.04^{*}$ & $0.01 \dagger$ & 0.56 \\
\hline Dryness & 0.66 & 0.31 & $0.02^{*}$ & 0.79 \\
\hline Grittiness & 一 & 0.31 & 0.15 & 一キ \\
\hline Burning & - & 0.31 & 0.08 & - \\
\hline Itching & 0.56 & 0.31 & 0.08 & 0.65 \\
\hline Foreign body & 一‡ & 0.18 & 0.15 & 0.78 \\
\hline Irritation & 一キ & $0.04^{*}$ & $0.01 \dagger$ & 0.41 \\
\hline Blurring & 0.66 & $0.03^{*}$ & $0.01 \dagger$ & 0.56 \\
\hline
\end{tabular}

the percentage of patients with intense symptoms for the control group.

\section{Correlations}

In the Sjögren syndrome group, the Pearson's correlation coefficient was $-0.59(P=0.002)$ for tear volume and $A_{5} A$. The value of this coefficient indicates a low to moderate degree of correlation and the negative sign means that the lower the result of the Schirmer test, the greater the level of $A p_{5} A$. With respect to nucleotides, the Pearson's correlation coefficient showed a moderate to high degree of correlation for $\operatorname{Ap}_{4} \mathrm{~A}(P=$ 0.024 ) with $\mathrm{Ap}_{5} \mathrm{~A}$ in the Sjögren syndrome group (Table 4 ).

In a previous work, it was possible to demonstrate the existence of differences between $\mathrm{Ap}_{4} \mathrm{~A}$ and $\mathrm{Ap}_{5} \mathrm{~A}$ concentrations and symptomatic and asymptomatic dry eye patients. ${ }^{9}$ In the present study, when trying to determine wether there were differences between any reported symptom and the concentrations of these dinucleotides in Sjögren syndrome patients, we did not find a statistically significant correlation between any reported symptom and the concentrations of these dinucleotides in Sjögren syndrome patients by ANOVA $(P>0.05)$.

\section{Discussion}

In the present work, the concentrations of $A p_{4} A$ and $A p_{5} A$ in patients with Sjögren syndrome were investigated. These values were increased 42- and 595-fold for $A_{4} A$ and $A p_{5} A$, respectively, compared with the control group. In the Sjögren syndrome subgroup with low tear secretion, the results showed that these patients had higher levels of the adenine dinucleotides $\mathrm{Ap}_{4} \mathrm{~A}$ and $A \mathrm{p}_{5} \mathrm{~A}$ in their tears than did Sjögren syndrome patients with normal tear secretion. These facts could suggest that these dinucleotides are potential tools for the diagnosis of dry eye, as previously related. 9

If we compare the data of Sjögren syndrome patients with those of non-Sjögren dry eye symptomatic subjects presented in a previous work (Table 1), ${ }^{9}$ the concentration of $\mathrm{Ap}_{4} \mathrm{~A}$ in patients with Sjögren syndrome with low tear secretion was less than half that in those non-Sjögren dry eye symptomatic patients with reduced tear secretion. In the Sjögren and the non-Sjögren dry eye groups with normal tear secretion, there were no differences in the concentrations of $\mathrm{Ap}_{4} \mathrm{~A}$. However, $\mathrm{Ap}_{5} \mathrm{~A}$ appeared in higher concentrations in patients with Sjögren syndrome compared with non-Sjögren dry eye subjects. This fact could indicate that $A \mathrm{p}_{5} \mathrm{~A}$ can be a differentiating factor between Sjögren syndrome and non-Sjögren dry eye.

Several works have reported that the ocular surface in Sjögren syndrome patients is altered and damaged. A positive ocular staining with fluorescein and rose bengal has been described in these subjects. ${ }^{18,19}$ The diadenosine polyphosphates have a hastening effect on the corneal re-epithelialization, and a greater release of $A p_{4} A$ and $A p_{5} A$ in tears will therefore help naturally to facilitate the rate of wound healing. ${ }^{11}$ It has been reported that an increased blinking frequency enhances the levels of nucleotides in tears, because of the shear stress provoked by the eyelids on the ocular surface, ${ }^{9}$ and an increase in the blinking frequency of dry eye patients has been reported. ${ }^{20}$ The damage to the ocular surface and the increased blinking rate in Sjögren syndrome patients could explain why the presence of diadenosine polyphosphates in these patients is higher than in healthy individuals.

TABLE 4. Correlation among Diadenosine Polyphosphates, Schirmer Test and Age in Sjögren Syndrome Patients

\begin{tabular}{lccccc}
\hline & & $\mathbf{A p}_{4} \mathbf{A}$ & $\mathbf{A p}_{5} \mathbf{A}$ & Schirmer Test & Age \\
\hline $\mathrm{Ap}_{4} \mathrm{~A}$ & Pearson correlation & 1 & 0.76 & -0.43 & 0.12 \\
& $P$ & - & $<0.01^{*}$ & 0.11 & 0.67 \\
$\mathrm{Ap}_{5} \mathrm{~A}$ & Pearson correlation & 0.76 & 1 & -0.59 & 0.28 \\
& $P$ & $<0.01^{*}$ & - & $0.02 \dagger$ & 0.32 \\
Schirmer test & Pearson correlation & -0.43 & -0.59 & 1 & -0.20 \\
\multirow{2}{*}{ Age } & $P$ & 0.11 & $0.02^{*}$ & - & 0.41 \\
& Pearson correlation & 0.12 & 0.28 & -0.20 & 1 \\
& $P$ & 0.67 & 0.32 & 0.41 & - \\
\hline
\end{tabular}

Pearson bivariate regression test to compare the possible correlation among nucleotides, Schirmer test and age.

${ }^{*} P<0.01$ (two-tailed).

† $P<0.05$ (two-tailed). 
It has been shown that $A_{4} A$ and $A p_{5} A$ stimulate tear secretion, ${ }^{10}$ and it appears that they are naturally released and serve to increase the tear volume and quality by stimulating the $\mathrm{P}_{2} \mathrm{Y}_{2}$ receptors present in meibomian and accessory glands. ${ }^{21,22}$ Although the presence of $\mathrm{P} 2 \mathrm{Y}_{2}$ receptors in the lacrimal gland has not yet been reported, these receptors have been found in the lacrimal gland of New Zealand White rabbit (Hoyle CHV, personal communication, 2009). Their presence in the salivary glands has been demonstrated. ${ }^{23}$ Schrader et al. ${ }^{24}$ indicated that $\mathrm{P} 2 \mathrm{Y}_{2}$ receptor expression is upregulated in the submandibular gland of the NOD.B10 mouse, a model of Sjögren syndrome, to provide a pathway for fluid secretion. Furthermore, Baker et al. ${ }^{25}$ reported that $\mathrm{P}_{2} \mathrm{Y}_{2}$ receptor activation in salivary gland cells increases the epidermal growth factor receptor (EGFR)-dependent expression of vascular cell adhesion molecule (VCAM)-1 and the binding of lymphocytes.

A similar effect may occur in the lacrimal gland of Sjögren syndrome patients, where the expression of the $\mathrm{P}_{2} \mathrm{Y}_{2}$ receptor may be augmented to increase tear secretion, but in fact provokes the lymphocyte infiltration that may lead to the inflammation associated with Sjögren syndrome. Although $\mathrm{Ap}_{4} \mathrm{~A}$ and $\mathrm{Ap}_{5} \mathrm{~A}$ are present at high concentrations in Sjögren syndrome patients, it seems to be that they are not able to stimulate more lacrimation. Instead they may be increasing lymphocyte infiltration. Further studies are needed to confirm our hypothesis that $\mathrm{P}_{2} \mathrm{Y}_{2}$ upregulation really occurs in lacrimal glands of Sjögren syndrome patients and to establish the purpose of this upregulation.

In normal individuals dinucleoside polyphosphates increase tear production. ${ }^{7}$ In contrast, some Sjögren patients lack this dinucleotide stimulation. Presumably, Sjögren patients with normal tear production have the benefit of the secretagogue action triggered by these molecules, in clear contrast with those who do not seem to be sensitive to these dinucleotides. It could be the case that the difference between these two subpopulations of Sjögren patients is due to factors such as a poorer tear quality that makes it more evaporative, or some problems with the lachrymal apparatus. There is no evidence of dysfunction of the $\mathrm{P}_{2} \mathrm{Y}_{2}$ receptors in the lachrymal gland, but such dysfunction may explain the lack of secretagogue activity for these substances in some Sjögren patients. This point should be investigated more thoroughly.

Concerning the Schirmer test results, it may be surprising that in a disease whose main sign is aqueous tear deficiency, patients have values of tear secretion above $10 \mathrm{~mm}$. Others studies have found similar results for the Schirmer test. ${ }^{18,19}$ This is probably due to the different severities of the disease and the poor sensitivity of the test. ${ }^{26}$

Another interesting point is the lack of correspondence between the increase in tear volume and the dinucleotide concentration. The present experiments demonstrated that when there was an increase in tear production, there was not a linear change in the dinucleotide concentration. Indeed dinucleotides were not "diluted" as expected, perhaps because of the way these compounds are released. In particular, diadenosine polyphosphates are released as a consequence of mechanical stress, ${ }^{9}$ which very often relates to an increase in the blinking frequency due to discomfort. ${ }^{\text {? }}$

Discomfort, light sensitivity, and dryness were the most frequent and intense symptoms, which is consistent with the results reported by other researchers. ${ }^{18}$ Sjögren syndrome patients reported that their symptoms increased later in the day, and they were more pronounced in the low tear secretion group, Versura et al. $^{27}$ suggested an environment or taskrelated etiology for dry eye symptoms as the main factor in increased intensity at the end of the day.
There were no statistically significant differences in $\mathrm{Ap}_{4} \mathrm{~A}$ and $A p_{5} A$ concentrations in tears from normal humans aged from 20 to 50 years (our unpublished data, 2010). Therefore, the difference in ages of the control and Sjögren syndrome groups is not a factor in the difference in diadenosine polyphosphate concentrations.

In conclusion, concentrations of diadenosine polyphosphates are increased in tears of Sjögren syndrome patients, especially $A p_{5} A$, which could be used as a diagnostic tool for this condition. In addition, we conclude that $\mathrm{Ap}_{4} \mathrm{~A}$ is increased in pathologic dry eye with respect to healthy eyes, confirming its role as an objective marker of dry eye.

\section{Acknowledgments}

The authors thank Thomas Millar and Charles H. V. Hoyle for help in the preparation of the manuscript.

\section{References}

1. Srinivasan S, Slomovic AR. Sjogren syndrome. Compr Ophthalmol Update. 2007;8(4):205-212.

2. Vitali C, Bombardieri S, Jonsson R, et al. Classification criteria for Sjogren's syndrome: a revised version of the European criteria proposed by the American-European Consensus Group. Ann Rbeum Dis. 2002;61(6):554-558.

3. Pillemer SR, Matteson EL, Jacobsson LT, et al. Incidence of physician-diagnosed primary Sjogren syndrome in residents of Olmsted County, Minnesota. Mayo Clin Proc. 2001;76(6):593-599.

4. Garcia-Carrasco M, Ramos-Casals M, Rosas J, et al. Primary Sjogren syndrome: clinical and immunologic disease patterns in a cohort of 400 patients. Medicine (Baltimore). 2002;81(4):270-280.

5. Vescovi P, Manfredi M, Cimarosti S. Sjogren's syndrome: clinical and therapeutic features: a review of the literature (in Italian). Minerva Stomatol. 2004;53(1-2):1-19.

6. Methodologies to diagnose and monitor dry eye disease: report of the Diagnostic Methodology Subcommittee of the International Dry Eye WorkShop. Ocul Surf. 2007;5(2):108-152.

7. Pintor J, Carracedo G, Alonso MC, Bautista A, Peral A. Presence of diadenosine polyphosphates in human tears. Pflugers Arch. 2002; 443(3):432- 436

8. McLennan AG. Dinucleoside polyphosphates: friend or foe? Pharmacol Ther. 2000;87(2-3):73-89.

9. Peral A, Carracedo G, Acosta MC, Gallar J, Pintor J. Increased levels of diadenosine polyphosphates in dry eye. Invest Ophthalmol Vis Sci. 2006;47(9):4053-4058.

10. Pintor J, Peral A, Hoyle CH, et al. Effects of diadenosine polyphosphates on tear secretion in New Zealand white rabbits. $J$ Pharmacol Exp Ther. 2002;300(1):291-297.

11. Pintor J, Bautista A, Carracedo G, Peral A. UTP and diadenosine tetraphosphate accelerate wound healing in the rabbit cornea. Opbthalmic Physiol Opt. 2004;24(3):186-193.

12. Pintor J, Peral A, Pelaez T, Martin S, Hoyle CH. Presence of diadenosine polyphosphates in the aqueous humor: their effect on intraocular pressure. J Pharmacol Exp Ther. 2003;304(1):342348.

13. Begley CG, Chalmers RL, Mitchell GL, et al. Characterization of ocular surface symptoms from optometric practices in North America. Cornea. 2001;20(6):610-618.

14. van Bijsterveld OP. Diagnostic tests in the Sicca syndrome. Arch Ophthalmol. 1969;82(1):10-14.

15. Pintor J, Torres M, Miras-Portugal MT. Carbachol induced release of diadenosine polyphosphates-Ap4A and Ap5A-from perfused bovine adrenal medulla and isolated chromaffin cells. Life Sci. 1991;48(24):2317-2324.

16. Pintor J, Diaz-Rey MA, Torres M, Miras-Portugal MT. Presence of diadenosine polyphosphates-Ap4A and Ap5A-in rat brain synaptic terminals: $\mathrm{Ca} 2+$ dependent release evoked by 4 -aminopyridine and veratridine. Neurosci Lett. 1992;136(2):141-144.

17. Acosta MC, Peral A, Luna C, Pintor J, Belmonte C, Gallar J. Tear secretion induced by selective stimulation of corneal and conjunc- 
tival sensory nerve fibers. Invest Ophthalmol Vis Sci. 2004;45(7): 2333-2336.

18. Begley CG, Chalmers RL, Abetz L, et al. The relationship between habitual patient-reported symptoms and clinical signs among patients with dry eye of varying severity. Invest Ophthalmol Vis Sci. 2003;44(11):4753-4761.

19. Barboza MN, Barboza GN, de Melo GM, et al. Correlation between signals and symptoms of dry eye in Sjogren's syndrome patients (in Portuguese). Arq Bras Oftalmol. 2008;71(4):547-552.

20. Tsubota K, Hata S, Okusawa Y, Egami F, Ohtsuki T, Nakamori K. Quantitative videographic analysis of blinking in normal subjects and patients with dry eye. Arch Ophthalmol. 1996;114(6):715-720.

21. Cowlen MS, Zhang VZ, Warnock L, Moyer CF, Peterson WM, Yerxa BR. Localization of ocular P2Y2 receptor gene expression by in situ hybridization. Exp Eye Res. 2003;77(1):77-84.

22. Yerxa BR, Mundasad M, Sylvester RN, Garden JC, Cooper M, Kellerman DJ. Ocular safety of INS365 ophthalmic solution, a P2Y2 agonist, in patients with mild to moderate dry eye disease. Adv Exp Med Biol. 2002;506:1251-1257.
23. Turner JT, Landon LA, Gibbons SJ, Talamo BR. Salivary gland P2 nucleotide receptors. Crit Rev Oral Biol Med. 1999;10(2):210224.

24. Schrader AM, Camden JM, Weisman GA. P2Y2 nucleotide receptor upregulation in submandibular gland cells from the NOD.B10 mouse model of Sjogren's syndrome. Arch Oral Biol. 2005;50(6): 533-540.

25. Baker OJ, Camden JM, Rome DE, Seye CI, Weisman GA. P2Y2 nucleotide receptor activation upregulates vascular cell adhesion molecule-1 [corrected] expression and enhances lymphocyte adherence to a human submandibular gland cell line. Mol Immunol. 2008; $45(1): 65-75$.

26. Farris RL, Stuchell RN, Mandel ID. Basal and reflex human tear analysis. I. Physical measurements: osmolarity, basal volumes, and reflex flow rate. Ophthalmology. 1981;88(8):852-857.

27. Versura P, Cellini M, Torreggiani A, Profazio V, Bernabini B, Caramazza R. Dryness symptoms, diagnostic protocol and therapeutic management: a report on 1,200 patients. Ophthalmic Res. 2001; 33(4):221-227. 